\title{
UMA ANÁLISE DO CONCEITO DE ZONA DE DESENVOLVIMENTO PROXIMAL
}

Alex Santos Bandeira BARRA*

*Graduado em Psicologia - PUC-2003, Mestre em Educação - UNB - 2007. alexbarrago@ yahoo.com.br

Recebido em: 14/04/2014 - Aprovado em: 30/06/2014 - Disponibilizado em: 30/07/2014

RESUMO

Este artigo faz uma discussão sobre o conceito de zona de desenvolvimento proximal demonstrando sua importância no contexto educacional e correlacionando com o conceito de interação social num primeiro momento. Posteriormente discutimos a questão da Prospeção e sua relação com o desenvolvimento e aprendizagem. Por último é feita uma discussão da relação entre o conceito de zona de desenvolvimento proximal ou aquilo que Vygotsky chamou de instrumento.

Palavras-Chave: Vygotsky; Educação; Psicologia da Educação.

\section{ABSTRACT}

This article makes a discussion about the concept of zone of proximal development demonstrating its importance in educational context and correlating it with the concept of social interaction in a first moment. Later we discuss the issue of Search and its relationship with development and learning. Finally there is a discussion about the relationship between the concept of zone of proximal development or what Vygotsky called instrument.

Keywords: Vygotsky; Education; Psychology of Education

\section{Introdução}

A teoria de Vygotsky está amplamente presente em textos da área de educação por pertencer a uma concepção teórica que melhor explica a relação desenvolvimento/aprendizagem. Pensando nisto desenvolveremos algumas reflexões acerca do conceito de Zona de Desenvolvimento Proximal.

Segundo Rego (2011) existem cinco pontos essenciais na teoria de Vigotski: 1) As funções psicológicas superiores são resultado da interação dialética do homem com o seu meio sociocultural; 2) as funções psicológicas superiores se originam nas relações do indivíduo e seu contexto social; 3) o cerébro é dotado de plasticidade; 4) As atividades humanas são mediadas por instrumenos e símbolos; 5) Os processos psicológicos não podem ser resumidos à simples reflexos condicionados.

\section{Zona de Desenvolvimento Proximal e} Interação Social

A Zona de Desenvolvimento Proximal (Z.D.P.) é caracterizada por Vygotsky (2000, p. 112) como: "a distância entre o nível de desenvolvimento real, que se costuma determinar através da solução independente de problemas, e o nível de desenvolvimento potencial, determinado através da solução de problemas sob a orientação de um adulto [...]". Ao fazer esta afirmação Vygotsky entende que o desenvolvimento real é aquilo que a criança já 
aprendeu. O nível de desenvolvimento potencial é equivale àquilo que ela atingiu a partir da interação com o Outro, como por exemplo o professor.

O conceito de Z.D.P insere o elemento da interação como fundamento para a aprendizagem da criança. Ao afirmar que a criança aprende com o adulto, Vygotsky está confirmando a tese marxista de que é necessário um processo de mediação social para haver aprendizagem. "Mas a essência humana não é uma abstração inerente a cada indivíduo. $\mathrm{Na}$ sua realidade ela é o conjunto das relações sociais" (MARX, 1984, p. 109). O homem, a partir de Marx é entendido como um ser social pois está imerso numa relação essencialmente humana que superou a origem natural e biológica.

"Só o que podem fazer os animais é utilizar a natureza e modificá-la pelo mero fato de sua presença nela. O homem, ao contrário, modifica a natureza e a obriga a servir-lhe, domina-a" (MARX; ENGELS, 2004, p. 28). Ao contrário dos animais, o homem é um ser que tem domínio sobre a natureza; ao produzir cultura o homem utiliza sua consciência para transformar a natureza. $\mathrm{Ou}$, como disse Vygotsky (2000, p. 115) acerca da relação homem e animal: "um primata pode aprender bastante através do treinamento, usando as suas habilidades motoras e mentais; no entanto, não se pode fazê-lo mais inteligente, isto é, não se pode ensiná-lo a resolver, de forma independente, problemas mais avançados" (VYGOTSKY, 2000, p. 115). Somente os homens são capazes de aprender no sentido que conhecemos. Os animais, ao contrário, apenas conseguem reproduzir aquilo que aprendem. $\mathrm{Na}$ verdade, os animais são treinados, enquanto os humanos aprendem. "O aprendizado humano pressupõe uma natureza social específica e um processo através do qual as crianças penetram na vida intelectual daquelas que as cercam" (VYGOTSKY, 2000, p. 115).

Isso significa que a criança aprende mais e melhor quando interage na escola. Ela não aprende somente na escola. Mas na escola, a criança sempre interage, mesmo na sala de aula convencional, onde percebemos que a interação é mais afetiva e social que cognitiva uma vez que os docentes poucas vezes utilizam estratégias que exijam elaboração do raciocínio individual dos seus alunos, pois o que ainda se percebe é uma forte tendência do ensino tradicional ao nível metodológico, embora a relação professor-aluno seja mais próxima da concepção humanista. O aluno, subjugado na condição passiva, de apenas escutar o que o docente fala pouco interage. Embora ali haja interação a mesma ocorre de maneira mais social e afetiva e menos intelectual naquilo que poderia desenvolver toda a potencialidade do aluno. 
A Z.D.P permite que a troca social, isto é, a troca entre professor e aluno ocorra intelectualmente. Embora o conceito apresentado por Vygotsky saliente o aspecto social, é preciso destacar que o nível cognitivo é o mais importante. O professor porta o chamado conceito científico, e o aluno adentra a escola com o conceito cotidiano (SAVIANI, 2003). O conceito científico equivale aos conceitos a serem transmitidos pelo professor. Equivale à visão científica dos conceitos. Do outro lado, têm-se o conceito cotidiano que equivale a visão do senso comum, isto é, a concepção popular da realidade.

$\mathrm{O}$ professor - equivale à zona de desenvolvimento potencial (mais desenvolvido) - e o aluno, no ponto de partida, equivale à zona de desenvolvimento real (menos desenvolvido). Com o aprendizado - mediado pelo docente - o aluno deixará a condição de zona de desenvolvimento real e passará à zona de desenvolvimento potencial exatamente igual seu docente. Ao chegar nesta última, o processo se renova, tornando-se novamente zona de desenvolvimento real e "necessitando" aprender novamente. $\mathrm{O}$ processo de aprendizagem, e também de desenvolvimento são ininterruptos. No início o aluno age de maneira sincrética, e no final alcança o nível sintético (VYGOTSKY, 2000). O sincrético é algo pouco sistematizado. O sintético obedece ao entendimento correto das normas e do conhecimento científico. O sincrético está para o ponto de partida, assim como o sintético está para o ponto de chegada.

Poderíamos traduzir de outra maneira. $\mathrm{O}$ aluno no início do processo está atrasado. E seu professor adiantado. $\mathrm{O}$ adiantado, desenvolve o atrasado, isto é, o faz o mesmo avançar. Assim haverá o progresso. O professor - que corresponde ao adiantado - acelera o aluno através do ensino, utilizando estratégias de aprendizagem eficientes. É importante destacar que o fato de o docente representar a zona de desenvolvimento proximal (ontologicamente falando) não significa que pedagogicamente em sua aula haverá aprendizagem, na concepção defendida por Vygotsky. Em outras palavras: o ontológico não coincide com o pedagógico.

Se a aula tiver características tradicionais, então a tendência é a supervalorização do ensino sobre a aprendizagem; do professor ao invés do aluno; da teoria ao invés da prática (SAVIANI, 2003). Em síntese: não havá aprendizagem, pois o aluno assimila os conceitos de maneira passiva. Decora! Ele não reflete de maneira elaborada e tão somente memoriza. Podemos dizer: o aluno utiliza a memória mas pouco uso faz do raciocínio. Com isso, o docente pode não fomentar as reais capacidades do aluno, impedindo que o mesmo atinja o nível de zona de desenvolvimento proximal. A análise de Vygotsky modifica a visão tradicional 
"segundo a qual, no momento em que uma criança assimila o significado de uma palavra [...] seus processos de desenvolvimento estão basicamente completos" (VYGOTSKY, 2000, p. 118).

Os professores que ministram aula no modelo tradicional oportunizam apenas o nivel da aquisição e não da aprendizagem. A transmissão dos conceitos só "consolida" o desenvolvimento mas não estimula a aprendizagem. Portanto, o aluno tão somente decora, mas não raciocina. Quando o processo está finalizando na escola é que deveria iniciar. "Na verdade, naquele momento eles apenas começaram" (VYGOTSKY, 2000, p. 118). Isso significa que o professor tradicional promove apenas o nível do desenvolvimento. É como se ele ficasse preso à parte teórica. $\mathrm{O}$ aluno não vê sentido na parte prática. Isto é, não consegue enxergar a aplicabilidade do conceito. E, mesmo que o docente exemplifique os conceitos, ainda sim, o processo ficará em nível teórico, pois o aluno não fez a prática do conceito, pois foi o docente que enveredou pelo raciocínio. Dito de outra forma, se somente o docente raciocina, isso não é suficiente para produzir a zona de desenvolvimento proximal no aluno. Cabe ao aluno deduzir e induzir os conceitos. Dedução e indução correspondem à zona de desenvolvimento proximal.

\section{Zona de Desenvolvimento Proximal e} Prospecção

Por isso Vygotsky (2000, p. 113) afirma: “o nível de desenvolvimento real caracteriza o desenvolvimento mental retrospectivamente, enquanto a zona de desenvolvimento proximal caracteriza o desenvolvimento mental prospectivamente". Isso significa que a zona de desenvolvimento proximal leva o aluno para frente. Dá um impulso em sua cognição. Enquanto a zona de desenvolvimento real, apenas reproduz os conceitos transmitidos pelo docente.

Podemos dizer: a Z.D.R. equivale àquilo que a Escola Tradicional realiza. O professor, ao transmitir os conceitos de maneira puramente externa e teórica, não oportuniza ao aluno a chance dele criar. Não que isso não seja válido, enquanto ensino, mas é reduzido em termos de chances de aprendizagem. Em nível puramente teórico, a aula expositiva alcança somente a memória. Às vezes, nem mesmo a memória. No nível da retórica (exposição) a aula oferece a chance de visualizar os conceitos e "entendê-los" de maneira externa e pouco prática no cotidiano. $\mathrm{O}$ aluno não consegue apreender de fato o conceito, pois ele não realiza a dedução. Entendimento não equivale a aprendizagem. $\mathrm{O}$ entendimento produzido na aula tradicional apenas apresenta ao estudante a visualização na memória de curto prazo, ao contrário de um processo lógico que exige 
dedução. E, muitas vezes, esta visualização fica comprometida, pois em geral os docentes da educação básica poucas vezes oferecem recursos que promovam as imagens dos conteúdos ensinados. É comum os alunos não "enxergarem" os conteúdos ensinados na escola.

A dedução, tal como está sendo definida aqui, equivale a aprendizagem. A dedução, corresponde à lógia dos conceitos e como tal constitui o verdadeiro processo do raciocínio que pode se realizar num determinado conteúdo. Vygotsky esclarece: “o aprendizado é mais do que a aquisição de capacidade para pensar; é a aquisição de muitas capacidades especializadas para pensar sobre várias coisas" (VYGOTSKY, 2000, p. 108). Pensar é mais que assimilar conceitos de maneira passiva. Pensar equivale a fazer relações entre $o$ conceito e a realidade. E, entre os próprios conceitos.

A Z.D.P. modifica de maneira especifica o pensamento sobre determinados conceitos pois a aprendizagem equivale a "aquisição de muitas capacidades especializadas para pensar sobre várias coisas" (VYGOTSKY, 2000, p. 108). A especialidade da aprendizagem torna o processo qualitativamente mais interessante. Embora, muito se discuta na atualidade sobre interdisciplinaridade, Vygotsky vai de encontro à noção disciplinar. Isso, não significa que
Vygotsky é defensor da concepção de educação formal, que entende que o raciocínio apreendido em matemática, por exemplo, servirá para ser aplicado em geografia, por exemplo. Segundo Vygotsky isso ocorrerá se “o treino especial afeta o desenvolvimento global somente quando seus elementos, seus materiais e seus processos são similares nos vários campos específicos" (VYGOTSKY, 2000, p. 108). Com isso, Vygotsky defende a necessidade da especialidade sobre a generalidade. Segundo ele, nossa capacidade de raciocínio advém de processos internos em determinada disciplina que afetam nossa inteligência de maneira específica. E, não de maneira geral e global, como alguns pesquisadores defendem. "O desenvolvimento da consciência é o desenvolvimento de um conjunto de determinadas capacidades independentes ou de um conjunto de hábitos específicos” (VYGOTSKY, 2000, p. 108).

Alguns pesquisadores tendem a transformar o conceito específico de zona de desenvolvimento proximal em algo geral. Ou, comete-se um segundo erro: pensa-se a Z.D.P apenas pelo viés social esquecendo-se sua tessitura cognitiva. Nas duas posições cometese equívocos. Primeiro, porque ao se conceituar a Z.D.P de maneira global, está se desvalorizando a especificidade dos conteúdos curriculares. Além disso, está se incentivando a indução, quando na verdade, deveria haver a 
dedução. Induzir equivale a demonstrar algo geral a partir do particular. E, deduzir equivale a demonstrar algo particular a partir do geral. $\mathrm{O}$ erro está em associar a Z.D.P ao processo de indução, reduzindo a importância da Z.D.P pois o processo de aprendizagem na escola, quando ocorre verdadeiramente no sentido da aprendizagem, caminha pela descoberta individual (dedução) e não pela simples generalização (indução).

O segundo erro, é que ao reduzir o conceito a seu viés social está se retirando sua maior importância que é originariamente cognitiva. Vygotsky foi influenciado pelo teoria marxista. No entanto, suas teses caminharam no sentido de afirmar a teoria marxista numa acepção individual e não social como fez Marx. Vygotsky atestou a mudança evolutiva do macaco em homem a partir da aprendizagem. Vygotsky continua a teoria marxista em âmbito psicológico, embora tenha utilizado conceitos filosóficos.

Igualar a Z.D.P a uma leitura puramente social é retirar seu valor iminente. Pois a interação social é, como ponto de partida, tão somente convivência. $\mathrm{O}$ fato de os alunos estarem em sala de aula juntos não os torna capacitados para agirem como Z. D. P, pois a cooperação entre os colegas pode ser meramente social e nada cognitiva. Aliás, o que ocorre na aula tradicional é justamente isso: os alunos estão uniformemente dispostos de maneira a jamais questionarem aquilo que é transmitido pelo docente. Na aula tradicional o aluno só produz a confirmação dos conceitos transmitidos pelo docente e não seu questionamento. A confirmação repete a decoreba. O questionamento pode produzir dedução já que é o primeiro passo para a elaboração.

Portanto, a concepção da Z.D.P permite verdadeiro avanço do aluno. "Aquilo que é zona de desenvolvimento proximal hoje, será o nível de desenvolvimento real amanhã - ou seja, aquilo que uma criança pode fazer com assistência hoje, ela será capaz de fazer sozinha amanhã" (VYGOTSKY, 2000, p. 113).

Isso significa que quando existe a interação cognitiva, automaticamente gera-se a prospecção. $\mathrm{O}$ aprendizado produz no aluno a chance de agir independentemente. Independência não é isolamento. A visão restrita da psicologia hereditária, entendia o desenvolvimento apartado do aprendizado. Isto é, via o indivíduo isolado e naturalmente capaz de se desenvolver. A visão de Vygotsky é radicalmente oposta. Ele pensa o indivíduo de maneira social e, portanto, imerso nas relações sociais.

Cognitivamente falando há um processo de independência mas isso não significa falta de interação. A partir do instante que a criança se desenvolve, tendo atingido o nível de zona de desenvolvimeto potencial, automaticamente, 
em sua interação ela continuará dialeticamente alcançando sucessíveis níveis de desenvolvimento potenciais. $\mathrm{O}$ processo de interação continuamente dará ao estudante a chance de aprender mais. Conforme exposto anteriormente, no entanto, a simples interação não é suficiente para produzir novas mudanças em nível da lógica, pois nem sempre a mediação social alcança novos níveis de aquisição de conceitos. Duas pessoas podem estar conversando, sem necessariamente modificarem seu nível de aprendizado. Se o nível mental das duas pessoas for o mesmo, considerando a teoria vygotskyana, o que ocorre é um mero processo de troca social. "O estado de desenvolvimento mental de uma criança só pode ser determinado se forem revelados os seus dois níveis: o nível de desenvolvimento real e a zona de desenvolvimento proximal" (VYGOTSKY, 2000 , p. 113). Se os dois alunos estiverem no mesmo patamar de desenvolvimento real, não haverá nos dois a possibilidade de nova Z. D. P embora tenha havido troca social.

$\mathrm{Na}$ prática, o que acontece é que o processo de aprendizagem é mais simples e mais automático. A interação social produz aprendizagem constantemente mas não significa mudança de nível de desenvolvimento mental. O processo é tão comum que poucas vezes percebemos que estamos aprendendo. Isso ocorre porque, em geral, nosso processo de aprendizagem social é movido mais pela oralidade e menos pela escrita. Em geral, nossa sociabilidade é realizada através da fala no convívio diário com os amigos havendo a internalização superficial de conceitos. Às vezes, essa internalização ocorre de maneira automática e inconsciente. Podemos afirmar que está havendo aprendizagem, mas é uma aprendizagem mediana. Se o processo fosse pensado (planejar) e não somente aplicado (executar) certamente haveria mais desenvolvimento. É o que acontece por exemplo com o cantor. Aprende inicialmente a diferenciar entre um som mais agudo ou mais grave. Posteriormente aprende a melodia de uma música e começa a cantá-la. Sua aprendizagem continuará se reproduzindo pela melodia de outras músicas, assim como pela memorização das letras. Podemos dizer que há uma predominância da execução sobre o planejamento conforme Vygotsky (2000) elencou. Isso ocorre porque no convívio social existe uma tendência à reprodução constante, isto é, a automatização dos processos.

Evidentemente que se este aluno decidir ensinar o que está aprendendo certamente ele passará para um nível mais sofisticado de aprendizagem, em que a fala (cantar) e a audição (ouvir) da música não serão suficientes para a compreensão mais elaborada do conceito musical. Havendo um interesse pela escrita musical, no entanto, o processo será mais 
sofisticado. A escrita é mais sofisticada que a fala, conforme apontou Vygotsky. "O desenvolvimento da escrita não repete a história do desenvolvimento da fala. A escrita é uma função na estrutura como no funcionamento. Até mesmo o seu mínimo desenvolvimento exige um alto nível de abstração" (VYGOTSKY, 2008, p. 122/123).

$\mathrm{Na}$ interação social existe aprendizado mas este é realizado de maneira operativa e automática. Ocorre aprendizado, mas é menos complexo pois não atinge o nível abstrato do processo da escrita. Isso não quer dizer, no entanto, que a fala seja simples. $\mathrm{Na}$ verdade, a fala também exige certo grau de destreza. O processo, precisa da repetição para ser afinado, ao contrário da escrita. A escrita, não exige apenas a repetição, embora essa seja fundamental; mas exige-se também uma compreensão lógica das palavras, de sua sequenciação para fazer-se abstrata.

Portanto, o professor que oferece ao aluno a dedução, está oportunizando sucessíveis avanços em seu desenvolvimento. A escola, portanto, tem que perseguir a abstração dos conceitos.

\section{Zona de Desenvolvimento Proximal e} Atividades Manuais

A atividade manual equivale àquilo que Vygotsky chamou de instrumento. Sua gênese está na fundamentação feita por Marx sobre o trabalho. O "trabalho é um processo entre o homem e a natureza, um processo em que o homem, por sua própria ação, media, regula e controla seu metabolismo com a natureza" (MARX, 1985, p.36).

$\mathrm{Na}$ verdade, não existe separação entre trabalho manual e trabalho intelectual (MARX, 2002). No entanto, na sociedade capitalista fazse crer que essa separação seja adequada.

Conforme afirma Marx: "O homem só se sente como [ser] livre e ativo em suas funções animais, comer, beber e procriar, quando muito ainda habitação, adornos etc, e em suas funções humanas só [se sente] como animal. Animal se torna humano, e o humano, animal” (MARX, 2002, p. 83).

O trabalho manual é apenas a ilusão do homem pensado de maneira desespiritualizada. “[...] A perspectiva ontológica desenvolvida por Marx [...] nos mostra que é mediante o trabalho que os homens se produzem historicamente enquanto homens" (FRIGOTTO, 1992, p.07).

“As máquinas são a extensão dos braços e do cérebro humano e são parte da atividade humana, embora exista uma complexidade e multiplicidade nas operações desenvolvidas por essas máquinas" (SAVIANI, 1999). Pensar os dois aspectos de maneira separada é desconsiderar que o processo da consciência humana iniciou-se pela via do trabalho. "E quanto mais isso seja uma realidade, mais os homens sentirão e compreenderão sua unidade 
com a natureza, e mais inconcebível será essa ideia absurda e antinatural da antítese entre o espirito e a matéria" (MARX; ENGELS, 1998, p. 30).

A constatação que fazemos dessas afirmações é que existe uma relação entre a discussão sobre o trabalho manual e trabalho intelectual defendida por Marx e a relação entre instrumento e símbolo defendida por Vygotsky.

Quando, na criança, ocorre a unidade entre o instrumento e o signo, isto é, entre a atividade prática - trabalho manual - e o signo - trabalho intelectual, então "realiza-se, assim, o uso de instrumentos especificamente humano" (VYGOTSKY, 2000, p. 33). Significa que o processo de assimilação dos conceitos humanos é efetivamente humano quando ocorre a incorporação do objeto da ação na consciência da criança. É esse mesmo processo que precisa ser alcançado pelo aluno na escola.

\section{Considerações Finais}

Aprender equivale a incorporar o conceito seja do ponto de vista teórico como prático. O símbolo é o nome da ação. Atestouse isso a partir de Vygotsky (2000). Saber nomear as coisas é a gênese do que se chama ciência. Na prática, a ciência equivale às denominações dadas no mundo. É aquilo que o professor aprendeu, e é o que ele está repassando aos seus alunos. Se ele somente repassar, atingirá tão somente o nivel da transmissão. Se, no entanto, o aluno superar o meramente dado, sair do imediato para o mediato, ultrassando a aparência em direção à essência (Chauí, 2003), certamente ele aprenderá. Aprender é da ordem da inovação. Ouvir é da ordem da reprodução. Aprender é da ordem da criação. Cabe ao professor aprender com seus alunos. E, não somente lhes ensinar. O professor que somente ensina, não produz no aluno a chance de criar: ai o professor não aprende; aí o aluno somente reproduz. Fazer o aluno aprender é o desafio da criação intelectual. Criar em si, pode assemelhado ao conceito de Zona de Desenvolvimento Proximal.

\section{Referências Bibliográficas}

CHAUÍ, Marilena. Cultura e Democracia. 10. ed. São Paulo: Cortez, 2003a.

MARX, Karl; ENGELS, Friedrich. A Ideologia Alemã: teses sobre Feuerbach. São Paulo: Moraes, 1984.

REGO, T.C. VYGOTSKY. Uma Perspectiva Histórico-Cultural da Educação. 22ed Petrópolis: Vozes, 2011.

SAVIANI, D. Escola e democracia. $36^{\circ}$ Ed. Campinas, SP: Autores Associados, 2003; 
. Introdução. In: LOMBARDI, J. C;

SANFELICE, J.L.; SAVIANI, D (orgs).

História da educação: perspectivas para um

intercâmbio internacional. Campinas, SP:

Autores Associados, HISTEDBR, 1999;

VYGOTSKY, Lev. A formação social da mente. São Paulo: Martins Fontes, 2000;

. Pensamento e linguagem. São

Paulo: Martins Fontes, 2008; 